\title{
O FEMINISMO NA BOLÍVIA E SEUS REFLEXOS SOBRE A VIOLÊNCIA DE GÊNERO: A NECESSIDADE DE UMA ABORDAGEM INTERSECCIONAL
}

\author{
Letícia de Sousa Messias ${ }^{1}$
}

\section{RESUMO}

Diante da impossibilidade do feminismo hegemônico em compreender e colocar em pauta demandas das mulheres racializadas, a proposta é elucidar a luta das que possuem existência interseccional, dar enfoque à construção da luta feminista na Bolívia, em especial, através do feminismo comunitário, a sua compreensão das opressões e a forma de luta contra as amarras. Atrelado ao exposto, serão elucidadas as medidas que vêm sendo tomadas tanto pelos Poderes Legislativo e Judiciário quanto pela Articulación Regional Feminista até desembocar na análise da aplicação dos direitos das mulheres nas demandas ajuizadas diante da ocorrência de violência em decorrência do gênero.

Palavras-chave: Bolívia. Feminismo Comunitário. Interseccional. Poder Judiciário. Articulación Regional Feminista.

\section{FEMINISM IN BOLIVIA AND ITS REFLECTIONS ON GENDER VIOLENCE: THE NEED OF AN INTERSECTIONAL APPROACH}

\begin{abstract}
In view of the impossibility of the hegemonic feminism to understand and place racialized women's demands on the agenda, the proposal is to clarify the struggle of those who have an intersectional existence, to focus on the construction of the feminism in Bolivia, especially through community feminism, its understandings about oppressions and the way of fight. Linked to the above, the measures that have been taken by the Legislative, Judiciary and by Feminist Regional Articulation will be elucidated until it ends in the analysis women's rights applications in demands filed as a result of the occurrence of violence due to gender.
\end{abstract}

Keywords: Bolivia. Community Feminism. Intersectional. Judiciary. Feminist Regional Articulation.

\section{INTRODUÇÃO}

Inicialmente é importante ressaltar que a despeito de, em alguns momentos na evolução do feminismo, ser trazida a tona a discussão a respeito da relação entre orientação sexual, identidade sexual e gênero, não será foco da abordagem a discussão da temática. Com isso, será utilizado o termo mulher/mulheres como sujeitos aos quais são destinadas as abordagens feministas.

\footnotetext{
${ }^{1}$ Graduada e mestranda em Direito pela Universidade de São Paulo (FDRP/USP), leticiamessias@usp.br.
} 
O presente estudo se prestará a compreender a evolução do feminismo na Bolívia e, posteriormente, elucidar a relação atual existente entre mulheres bolivianas e violência de gênero. Para que seja possível alcançar o objetivo proposto, é necessário remontar toda a evolução das teorias feministas e seus reflexos na Bolívia, tendo em vista as particularidades que permeiam a realidade do país.

A discussão não se limita à evolução do feminismo hegemônico, decorrente de demandas do norte global. A despeito da sua relevância para a construção de um cenário internacional de reconhecimento de direito das mulheres e divulgação dos ideais, o intuito é compreender, de forma pormenorizada, a evolução do feminismo na Bolívia, quais aspectos políticos, históricos, jurídicos e legislativos levaram à construção da posição social das mulheres bolivianas na atualidade.

Nesse sentido, o intuito é seguir a proposta descrita por Matos (2010, p.68) e compreender o feminismo sob a perspectiva da nova onda, a qual tem em mente a importância de levar em consideração as fronteiras interseccionais, transversais e transdisciplinares entre gênero, raça, sexualidade, classe e religião.

A proposta é compreender como o feminismo sob a ótica de aspectos gerais e das posições de maior visibilidade não atende às demandas de grande parcela das mulheres, as quais possuem uma realidade e uma existência complexas, não é suficiente defender a evolução dos direitos de quem está em uma posição de maior destaque, é preciso compreender a realidade em sua totalidade, bem como a somatória de elementos que culminam na luta por existência das mulheres bolivianas.

No terceiro e quarto momentos do trabalho será possível relacionar a problemática do feminismo boliviano à violência de gênero no país, temas diretamente interligados, já que as demandas feministas possuem em seu âmago a busca pelos direitos das mulheres e fim das relações de abuso, exploração, opressão e silenciamento. A partir do exposto será possível correlacionar as demandas feministas com a realidade das mulheres bolivianas e compreender como os elementos discutidos teoricamente apresentam-se na realidade e nas demandas que as mulheres bolivianas levam ao Poder Judiciário.

\subsection{Objetivos}


Constitui-se como objetivo geral do presente trabalho a compreensão da evolução do feminismo na Bolívia, com base nas suas particularidades, e os reflexos na realidade descrita nas demandas judiciais que envolvem violência em decorrência do gênero.

Os objetivos específicos são compreender o motivo pelo qual o feminismo oriundo do norte global não atende as demandas das mulheres bolivianas; quais os principais elementos que permeiam a opressão das mulheres na Bolívia; quais medidas estão sendo tomadas para alteração do cenário e identificar como o patriarcado influencia nas decisões judiciais.

\subsection{Metodologia}

Para que seja possível realizar a abordagem proposta será realizada revisão bibliográfica e elaboração de um trabalho explicativo e descritivo da evolução do feminismo na Bolívia e como os elementos envolvidos nesse trajeto influenciam nas questões relacionadas à violência em decorrência do gênero.

A bibliografia utilizada como base para o trabalho, com raras exceções, foi inteiramente elaborada por mulheres, a escolha deve-se à busca por maior visibilidade dos trabalhos desenvolvidos por elas no âmbito acadêmico, tanto nacional quanto internacional.

As pesquisas desenvolvidas no Brasil que envolvem mulheres bolivianas, em sua maioria, buscam analisar a situação na condição de imigrante e não propriamente a sua condição social em seu país de origem. Pelo motivo exposto, no terceiro e quarto momentos do trabalho grande parte da bibliografia reproduzida é de origem estrangeira latino-americana, tendo em vista o enfoque da proposta que reside em compreender a evolução do feminismo na Bolívia e seus desdobramentos em relação à violência gênero no país.

\section{A VIOLÊNCIA DE GÊNERO E A REALIDADE ATUAL DAS MULHERES BOLIVIANAS}

É inquestionável que a realidade e as demandas das mulheres latino-americanas e, em especial, das mulheres bolivianas não são as mesmas das mulheres do norte global, porém, para que seja possível compreender o feminismo de acordo com as particularidades bolivianas, em um primeiro momento é necessário vislumbrar a evolução do feminismo sob 
uma perspectiva global e compreender o motivo pelo qual as demandas hegemônicas não atendem a existência interseccional da América Latina.

Usualmente são estudadas quatro ondas feministas, a partir do que é possível compreender as demandas e especificidades de cada um dos momentos sociais nos quais elas se inserem.

Conforme disposto por Maciel e Silva Neto, (2018, p.05), Marsha Laear foi a responsável por dar publicidade aos termos "primeira onda" e "segunda onda", além de destacar que a primeira onda, foi oriunda dos países do norte, como Reino Unido e Estados Unidos, fato relevante para a discussão que será travada no presente trabalho.

A primeira onda feminista está associada à Revolução Francesa de 1789 e possuía em seu âmago a reivindicação por direito, garantias fundamentais e autonomia econômica da mulher (JESUS; SACRAMENTO, 2014, p.02), o intuito era desvencilhar a posição da mulher do olhar lançado a ela, dos costumes e das imposições sociais.

A igualdade em relação aos homens era o que impulsionava as demandas da época, porém, é importante ressaltar que no período não havia unanimidade teórica em relação ao feminismo, em especial pela exclusão da discussão do campo acadêmico, o que obstava a teorização dos pensamentos e, consequentemente, a sua divulgação de forma organizada (LEGATES, 2011).

Tendo em vista que discussões fundamentais como direitos políticos e garantias mínimas foram o foco da primeira onda, a segunda onda foi responsável por trazer novas questões ao contexto, como as relacionadas à sexualidade, ao mercado de trabalho e às desigualdades decorrentes do âmbito jurídico (MACIEL; SILVA NETO, 2018, p.06).

Com a segunda guerra mundial e a necessidade de mão de obra, algumas oportunidades foram dadas ao trabalho feminino, porém, com o fim da guerra o trabalho doméstico voltou a ser a principal ocupação das mulheres, fato que impulsionou a pauta da segunda onda, a qual possuía em seu âmago a luta pela posição no mercado de trabalho.

A terceira onda, na década de 1990, deu início à visão interseccional da realidade das mulheres, ao passo que questionava o fato de que, até o momento, as discussões estavam voltadas à realidade de mulheres brancas do norte global. $\mathrm{O}$ momento é definido por Zinani (2011, p.408) como: “A Terceira Onda apresenta uma pauta de reivindicações mais ampla do que o grupo da Segunda Onda, uma vez que engloba a teoria queer, a conscientização da negra, o pós-colonialismo, a teoria crítica, o transnacionalismo, entre outros". 
Nesse sentido é possível identificar que a partir desse momento o intuito é compreender a realidade das mulheres sob uma perspectiva interseccional diante das complexidades que envolvem a sua realidade e existência. As demandas que visavam compreender a realidade de mulheres em condições de maior visibilidade deixaram de ser suficientes, a luta passou a ser por uma visão interseccional do feminismo.

$\mathrm{Na}$ realidade latino-americana diversos aspectos recaem sobre a existência das mulheres, o mecanismo de inclusão/exclusão segue um roteiro próprio, o qual atravessa várias questões, como a diversidade étnica e cultural (FENEMÍAS, 2007, p.12), conforme disposto por Femenías,

[...]la sociedad latinoamericana está fundada sobre tres raíces poblacionales fundamentales: la autóctona indígena, la europea "blanca" y la "negra" (a las que más recientemente se sumaron migraciones asiáticas); donde las cuestiones propias del feminismo postcolonial, del multicultural, del ecofeminismo, del pensamiento de la subalternidad, adoptan el diseño de las políticas de la identidade (2007, p.11).

A despeito das discussões em relação à constituição e demandas da quarta onda, esta será considerada como a que possui enfoque na realidade latino-americana e será a explorada no presente trabalho. Para ser possível compreender a realidade das mulheres bolivianas é necessário ter em mente uma abordagem interseccional, conforme delineada pelo feminismo latino-americano e disposto por Cypriano (2013, p.11), é preciso olhar a situação das mulheres sob uma perspectiva transnacional, capaz de abarcar interseções entre gênero, nacionalidade, raça, sexualidade e exploração econômica.

\section{A EVOLUÇÃO DO FEMINISMO NA BOLÍVIA}

Diante de todo o exposto, já é possível vislumbrar que a discussão feminista não se restringe a questões atreladas ao gênero, mas abrange a construção social como um todo e a forma por meio da qual o gênero se inter-relaciona com outros aspectos que permeiam a realidade, fato que coloca em cheque inclusive a percepção linear criada pelas "ondas feministas", permeada pela ideia de evolução e de existência de um marco zero a partir de uma perspectiva hegemônica.

A posição das mulheres bolivianas, a luta por direitos, por voz na sociedade e, consequentemente, a evolução do feminismo em território boliviano ocorreram de forma 
entrelaçada com os demais elementos que permeiam a construção da sociedade, não é possível desvencilhar as discussões feministas que foram travadas na Bolívia do aspecto político do país e de como ocorreu a sua construção histórica. Conforme disposto por Ortiz (2011, p. 160): “Actualmente, el patriarcado forma parte de la estrutura de poder em todas las sociedades del planeta aunque, por certo, no se expressa de la misma manera em todas las culturas".

Em 1929 ocorreu o advento da Convenção Feminina, uma organização de mulheres que possui como finalidade a busca por uma sociedade autônoma, tanto em relação aos aspectos intelectuais e artísticos quanto públicos, o intuito era a busca por direitos civis e políticos das mulheres, como direito ao voto, à educação e ao divórcio (ALLIÓN, 2015, p. 20).

A Convenção de 1929 impulsionou as discussões iniciais a respeito de aspectos intelectuais, artísticos e públicos da realidade das mulheres, mesma época na qual ocorreu o advento do movimento das mulheres anarquistas e, consequentemente, das discussões que envolvem a falta de representatividade do movimento feminista dentro da Bolívia, o qual era composto por mulheres de classe alta (ALLIÓN, 2015, p. 13).

Mesmo dentro do primeiro impulso boliviano para a reivindicação de direitos pelas mulheres, é possível identificar uma nova segregação, tendo em vista que havia uma diferença de classe entre as mulheres que compunham o movimento. Existia tanto uma perspectiva das mulheres oriundas das classes média e alta quanto uma luta decorrente das mulheres trabalhadoras e das classes menos abastadas, dentre as quais estavam as mulheres indígenas (ALLIÓN, 2015, p.21).

O disposto acima representa de forma cristalina a complexidade envolvida na luta feminista, tendo em vista que dentro do mesmo movimento, do mesmo país, do mesmo momento, ainda existem divergências e condições sociais totalmente diversas entre as mulheres. Mesmo dentro do cenário boliviano, não é possível lançar um olhar único ao feminismo, é necessária atenção às nuances, em especial em relação às mulheres indígenas, as quis compõe grande parte da sociedade, porém, não ocupam lugar de visibilidade.

Enquanto no cenário mundial ocorria o desenvolvimento da primeira onda feminista, na Bolívia as discussões estavam também em evolução, porém, sob uma perspectiva interseccional da realidade das mulheres bolivianas. 
Em um segundo momento, na década de 1980, foi possível identificar uma alteração no foco da perspectiva feminista na Bolívia, assim como no âmbito internacional. Na mesma época em que ocorreu o advento da segunda onda feminista, em território boliviano foram inseridas, de forma mais veemente, discussões a respeito da questão de violência em decorrência gênero e, consequentemente, em relação à necessidade de estabelecimento de diálogo com as políticas públicas.

Nesse sentido dispôs Allión,

Este enfoque de la teoría de género devino en una pragmática asentada em proyectos de desarrollo que favorecían la incorporación de la mujer en el ámbito productivo (sobre todo en la versión de pequeñas empresas), proyectos de salud reproductiva, de educación popular, de incoproración de las mujeres a la política pública y otros. Esta perspectiva pragmática, a veces sustentada en conceptos como la discriminación positiva o acción positiva, proveniente del feminismo de la igualdad, muchas veces redujo ámbitos grandes como los derechos de la mujer al de la violencia contra la mujer, tópico que se ha convertido hasta hoy en el epítome de las acciones a favor de la mujer (2015, p. 16).

Nesse contexto, as disposições legislativas buscavam acompanhar a evolução das demandas do feminismo. A Lei $\mathrm{n}^{\circ}$ 1779/1997 foi responsável por fortalecer os direitos políticos das mulheres bolivianas, o artigo $5^{\circ}$ trouxe a principal inovação capaz de legitimar a luta feminina na época, ao passo que estabeleceu um mínimo de candidaturas que obrigatoriamente deveria ser destinadas a mulheres, uma em cada três: “c) De candidatos a Diputados plurinominales por cada departamento, en estricto orden de prelación de Titulares y Suplentes. Estas listas incorporarán un mínimo de $30 \%$ de mujeres distribuidas de modo que de cada tres candidatos al menos uno sea mujer".

Merece destaque ainda o embrião que daria embasamento à criação da atual Lei 348/13, a Lei 1674/95 tratava da violência doméstica e familiar, com o intuito de estabelecer medidas imediatas para proteção das mulheres e diretrizes nacionais para erradicação da violência doméstica.

Avançando um pouco mais na linha do tempo do feminismo boliviano, na década de 1990 foi possível identificar um reforço dos ideais presentes na Convenção de 1929, ao passo que com o advento do feminismo autônomo, as reivindicações oriundas de contextos silenciados passaram a ganhar força no cenário nacional.

Em momento recente passou a ganhar força o feminismo anarquista e, com ele, as demandas relacionadas à diversidade sexual, o que foi possível por meio do respaldo de ONGs (ALLIÓN, 2015, p.17). No contexto descrito, com apoio político de Evo Morales 
passou a ganhar força o feminismo comunitário e a sua nova perspectiva em relação ao patriarcado e à construção social como um todo.

As diferenças da abordagem realizada pelo feminismo comunitário podem ser observadas na descrição de Paredes,

[...] a diferencia de otros feminismos, para los cuales el patriarcado es solamente la relación de poder y de dominación de los hombres hacia las mujeres, una especie de subsistema de otro mayor que, para los socialistas, es el capitalismo y, para los indianistas, es la colonia y la colonización. Para nosotras el sistema mayor es el Patriarcado (2015, p. 102).

No mesmo sentido reforça Guzmán e Paredes,

Para nosotras, el Patriarcado "es el sistema de todas las opresiones, todas las explotaciones, todas las violencias y dis-criminaciones que vive toda la humanidad (mujeres, hombres y personas intersexuales) y la naturaleza, históricamente construida, sobre el cuerpo de las mujeres" (2014, p. 77)

A perspectiva que é dada ao patriarcado o coloca em posição de destaque como elemento capaz de influenciar toda a construção do cenário social. A forma de opressão imposta pelo patriarcado é a responsável por moldar toda a sociedade, ele deixa de ser um dos elementos responsáveis pela construção de uma sociedade opressora e passa a ser o elemento central a partir do qual são desenvolvidos os demais aspectos sociais.

As demandas nesse momento são muito mais ambiciosas, além da necessidade de luta constante pelos direitos decorrentes de momentos anteriores, o objetivo atual é colocar a mulher em posição de destaque não só da sua vida, mas também das instituições tanto privadas quanto públicas.

A perspectiva do feminismo comunitário confere maior espaço ao protagonismo das mulheres que usualmente eram silenciadas nos demais movimentos de busca por direitos na Bolívia, as mulheres descendentes dos povos originários ganham maior visibilidade ao passo que a discussão a respeito da necessidade de luta pelo fim da colonialidade ganha força. Conforme disposto por Paredes (2015, p. 110): “De igual a igual, hablando en lenguaje propio, el significado detrás del término "feminismo" es otro, está pensado desde nosotras, desde nuestros cuerpos de mujeres de pueblos originarios empobrecidos por el capitalismo".

Diante dos pilares do feminismo comunitário, é realizada nesse momento uma crítica incisiva em relação à atuação dos feminismos oriundos do norte global, ao passo que eles não são suficientes para atender às demandas das mulheres latino-americanas, as mulheres que os 
constituíram e que estabeleceram suas lutas neles possuem realidades totalmente distintas das enfrentadas no sul.

Os questionamentos em relação à atuação do feminismo internacional sob uma perspectiva do norte global fazem parte da proposta do feminismo comunitário, o qual visa o fornecimento de maior visibilidade às realidades silenciadas, em especial dos povos originários bolivianos.

Nesse contexto passam a ser discutidos, sob uma nova perspectiva, conceitos essenciais que estão nos primórdios da construção das sociedades latino-americana: o patriarcado e a colonialidade, a partir do que são discutidos os seus efeitos em uma sociedade que teve o seu desenvolvimento a partir da opressão da colonização, o que influenciou na forma por meio da qual o patriarcado se instalou nos espaços sociais.

\subsection{A colonização como pilar na formação dos ideais feministas na Bolívia}

Conforme já elucidado, é necessário que o feminismo seja compreendido sob uma perspectiva interseccional. Nesse sentido, a proposta é elucidar os principais elementos que, estão diretamente interligados à construção da realidade das mulheres latino-americanas, tendo em vista as peculiaridades que acarretaram a construção social nos moldes atuais.

O questionamento em relação ao fim da colonialidade foi uma questão que passou a receber maior enfoque em território boliviano após as considerações realizadas pelas feministas comunitárias, ao passo que para a compreensão das demandas das mulheres é necessário ter uma perspectiva que remonte a realidade estudada, é preciso entender os reflexos do colonialismo que desembocaram na posição atual das mulheres, em especial, na Bolívia e que ainda estão presentes na realidade analisada.

Este posicionamiento de conceptos y propuestas desde el feminismo comunitario y
esta manera de nombrar nuestras prácticas políticas desde nuestros cuerpos y desde
nuestra historia, es lo que llamamos la descolonización del feminismo y la
descolonización de nuestras vidas, que finalmente nos permite mirar al espejo sin
temor a encontrarnos; más bien dignas y orgullosas de lo que vemos (PAREDES,
2015, p, 111).

Tendo em vista a história da América Latina, é evidente a existência de problemáticas que envolvem a colonização e a colonialidade. A construção social dos países foi impulsionada pelos elementos que permeiam a sua história, não é possível falar na 
construção da realidade boliviana sem ter em mente os povos originários e o tratamento que lhes foi conferido pelos colonizadores.

A colonização e os seus desdobramentos são elementos que unem toda a América Latina, o que envolve a situação dos povos originários que tiveram a sua história marcada pela exploração e pelo silenciamento das histórias que refletem a sua existência. Nesse sentido, é necessário compreender as profundas dificuldades que as mulheres, as quais destoam da condição de europeia-intelectual-branca, enfrentaram.

A brutalidade do tratamento aos povos originários chegava a acarretar a sua desumanização, tendo em vista que os colonizadores sequer os consideravam como seres humanos, tal fato reflete ainda de forma mais cruel sob as mulheres, ao passo que além da condição de não europeia existe ainda a visão lançada sobre elas em decorrência do gênero. Conforme preleciona Lugones,

\footnotetext{
A "missão civilizatória” colonial era a máscara eufemística do acesso brutal aos corpos das pessoas através de uma exploração inimaginável, violação sexual, controle da reprodução e terror sistemático (por exemplo, alimentando cachorros com pessoas vivas e fazendo algibeiras e chapéus das vaginas de mulheres indígenas brutalmente assassinadas) (2014, p. 938).
}

Ao distinguir os termos colonização e colonialidade, Lugones (2014, p. 939) elucida o fato de que a despeito de ter ocorrido o fim da colonização, a colonialidade ainda está presente na realidade social. É elucidado como a intersecção ente gênero, classe e raça ainda sofre pressão e falta de reconhecimento pelo sistema capitalista e patriarcal, tendo em vista que em tais situações a opressão é decorrente de variados fatores que permeiam a existência e as coloca em uma posição ainda mais vulnerável.

Diante do exposto é possível identificar que a herança dos primórdios da América Latina ainda acompanha a realidade das mulheres, já que até o momento não foi possível desvencilhar as amarras decorrentes da exploração e do silenciamento ocorrido há séculos. A necessidade da compreensão do feminismo sob uma perspectiva interseccional reside justamente na busca por compreensão da realidade complexa das mulheres que não se enquadram nos padrões aos quais estão relacionados ao feminismo hegemônico.

Não é possível apartar a realidade atual de aspectos que refletem a história dos povos originários de determinado território. Nesse sentido Lugones (2014, p. 944) destaca que na nova Constituição Boliviana o governo e os movimentos indígenas expressaram um compromisso com a filosofia suma qamaña, traduzida como "bem viver". O apoio de Evo 
Morales aos povos originários foi um dos elementos responsáveis por impulsionar uma maior discussão no país a respeito da temática, em especial sob uma perspectiva feminista.

[...]la elección de Morales ha desencadenado una serie de rupturas en los imaginarios que legitimaban nociones de superioridad e inferioridad. Al respecto, un punto no trivial de quiebre es la interpelación simbólica que conlleva el nombrar a mujeres indígenas en cargos jerárquicos del Estado[...] (Carrasco, 2013, p. 77).

Especificamente na Bolívia, é possível identificar apoio das instituições públicas para a aplicação das discussões na busca pelo combate à colonialidade e a sua utilização como ideologia e estratégia de poder, sendo que para emplacar essa luta, é necessário que o povo se reconheça como colonizado (ORTIZ, 2011, p.162).

A necessidade de mudança estrutural é tão profunda que existem membros que sequer se reconhecem como parte de um povo que foi silenciado pela Europa. Para que seja possível promover as alterações propostas é necessário que haja uma mobilização social conjunta, não apenas no âmbito da desconstrução feminista, mas da sociedade como um todo.

Nesse sentido é o entendimento descrito por Ortiz,

[...] la sola enunciación del objetivo trascendente de la descolonización marca el hito fundacional de subversión del orden instituido en la conquista española y sostenido durante toda la República. Los estigmas que dejó el colonialismo en la conciencia nacional son tan profundos y arraigados que me resulta inimaginable un proceso de descolonización de efectos inmediatos o de mediano plazo (2011, p.163).

A despeito da consideração realizada acima, é importante remontar que o objetivo do presente trabalho é elucidar a utilização do colonialidade como mecanismo de silenciamento das mulheres latino-americanas, assim como a sua relação com outros elementos sociais, como o patriarcado. A complexidade do cenário que envolve as mulheres bolivianas deixa evidente que movimentos feministas oriundos do norte global não são capazes de compreender a sua realidade e, consequentemente, reivindicar seus direitos de acordo com as reais demandas.

\subsection{A luta feminista boliviana pelo fim do patriarcado}

Para ser possível compreender a perspectiva boliviana proposta a respeito da intersecção entre colonialismo e patriarcado é necessário ter em mente as pautas do coletivo 
Mujeres Creando, o qual está vinculado ao feminismo comunitário, já exposto acima como uma das propostas para a compreensão das demandas feministas.

Uma das lutas corriqueiramente presente é a pela despatriarcalización, o seu advento ocorreu por meio do movimento feminista Mujeres Creando sob o lema: "No hay descolonización sin despatriarcalización” (ORTIZ, 2011, p. 165).

A visão é no sentido de que as formas de dominação estão intimamente relacionadas, ao passo que o patriarcado seria um dos elementos utilizados pelo colonialismo como instrumentos para imposição de limites e padrões sobre as mulheres.

Nesse sentido Alfaro descreve a proposta do coletivo a respeito da compreensão das formas de dominação,

\footnotetext{
Sin embargo, da una proyección inesperada y creativa a la meta heredada del órgano matriz del que se desprende —la "descolonización de la razón patriarcal paralelamente al resarcimiento de las desigualdades (sociales, económicas, sexuales, étnicas, culturales, políticas) sobre las que opera el sistema democrático liberal" (E. Monasterios 157) - cuando adopta el nombre de Mujeres Creando Comunidad y se dedica a la tarea de construir un feminismo comunitario alimentado por la "herencia anarquista de las luchas feministas anticoloniales" (2010, p.203).
}

Para compreender de maneira conjunta o colonialismo e o patriarcado é preciso vislumbrar a herança decorrente da forma que os europeus adentraram o solo latinoamericano e nele exploraram, tiraram a voz e as oportunidades dos povos originários.

A brutalidade por meio da qual ocorreu a dominação da sociedade existente trouxe em seu âmago o patriarcado, com isso, a proposta que visa o fim do patriarcado vai de encontro a toda herança colonial, o objetivo é desestabilizar as relações de poder e domínio existentes na sociedade, as quais surgiram por meio da dominação colonial (ORTIZ, 2011, p. 166).

A partir do momento que o patriarcado foi enraizado na sociedade ele passa a se moldar aos mais diversos cenários e a influenciar o dia-a-dia das mulheres de diversas formas. Paredes (2015, p. 106) reconhece que o patriarcado se recicla, ele se adapta às revoluções e às mudanças sociais, mas não deixa de estar presente. Mesmo com o fim formal da colonização, o patriarcado e os reflexos da construção social decorrentes dele ainda estão presentes na realidade das mulheres bolivianas. 
É possível identificar que a proposta não visa a formalização de direito das mulheres, mas propriamente uma alteração social, uma mudança de pilares nos quais estão calcadas as construções sociais.

O feminismo comunitário possui como proposta o seu nascimento descolonizado e antipatriarcal, conforme disposto por Paredes (2015, p. 109), o intuito é viver bem para todos os povos do mundo e para a natureza.

O objetivo é construir uma sociedade na qual a mulher não apenas tenha parcela de participação nas suas principais atividades, mas que, elas, de fato, sejam capazes de delinear os rumos do país de acordo com as suas demandas, através de uma perspectiva atenda às especificidades das necessidades dos grupos de mulheres a depender da sua condição social e das complexidades e elementos que envolvem a sua existência.

\section{O CENÁrio ATUAL dO FEMinismo NA bolívia a PARTiR do SEU ASPECTO INTERSECCIONAL}

Após compreender o cenário no qual está inserido o feminismo latino-americano, a origem e contexto no qual surge a demanda das mulheres bolivianas, será remontada a realidade atual em relação à violência de gênero.

A despeito de a violência não ser a discussão principal de muitos movimentos feministas explanados anteriormente, evidente que o tema está presente em um contexto no qual se fala de luta por direitos, por igualdade, por lugar de fala e por uma vida livre das amarradas da colonialidade e do patriarcado.

Ao analisar o cenário na Bolívia, é possível identificar que a questão da violência em decorrência do gênero é reconhecida como um problema social, os poderes públicos e as instituições estão atentos à questão e vêm tomando medidas com o intuito de dar maior abertura à discussão do tema, bem como estabelecer parâmetros de atuação quando identificada a sua ocorrência.

Atualmente, a Lei 348/13 é a responsável por tratar da questão da violência tanto física quanto psicológica e/ou sexual, tanto no âmbito familiar quanto no social. Conforme disposto pelo Ministério da Justiça (2014, p.185), foi necessário um longo percurso até a aprovação da legislação, motivo pelo qual a sua vigência constitui-se um grande avanço para 
o direito das mulheres, porém, ainda é evidente que o dispositivo legal não foi suficiente para alterar, de forma substancial, a realidade da Bolívia.

Diante do cenário descrito, a proposta do presente trabalho emergiu da necessidade de discussão a respeito da violência de gênero a partir de uma perspectiva que seja capaz de relacionar a temática às mulheres bolivianas. Para que seja possível realizar uma análise a respeito da perspectiva histórica do feminismo e do seu impacto na realidade da Bolívia.

A relevância do tema pode ser observada diante da crescente atrelada à violência em decorrência do gênero, fato que impulsionou inclusive a discussão a respeito da necessidade do advento de um alerta nacional sobre a temática (AGÊNCIA BRASIL, 2020). Com o intuito de reverter o cenário exposto, os Poderes Legislativo e Judiciário do país mostram-se atuantes no sentido de discutir e buscar medidas para a redução dos abusos sofridos pelas mulheres.

Nesse sentido merece destaque a Lei 348/13, a qual possui como principal objetivo garantir o direito às mulheres de não sofrer qualquer tipo de violência física, sexual e/ou psicológica, tanto no âmbito familiar quanto na sociedade, sob uma abordagem complementar à Lei 1674/95, intitulada Lei de Violência Familiar e Doméstica.

Foi percorrido um longo caminho até a promulgação da legislação nos moldes existentes hoje. Conforme disposto por Dávalos (2014, p.185), representante do Ministério da Justiça, foram cerca de dez anos de discussão até ser possível dar o passo em direção à garantia do direito das mulheres. Porém, ao continuar seu discurso, fica evidente que unicamente a disposição legal não é suficiente para alteração do cenário social boliviano.

Com o intuito de conferir maior força às garantias dispostas na Lei 348, no dia 08 de março de 2017, o Comitê de Gênero do Órgão Judicial foi o responsável por lançar o protocolo para defender a vida, a dignidade e os direitos das mulheres, com o intuito de dispor, de forma imperativa, como os operadores do sistema de justiça devem se portar.

A esse respeito dispôs a magistrada Cinthia Armijo, responsável por presidir o comitê:

\footnotetext{
"Este protocolo es de aplicación obligatoria para jueces, vocales y magistrados a nivel nacional porque ha sido aprobado mediante el Acuerdo de Sala Plena No. 126/16 del TSJ y es de conocimiento de los más de 1.000 jueces de Bolivia para que sea implementado de manera imperativa para que en las sentencias no exista ningún tipo de discriminación hacia la mujer que pueda mellar su dignidad ni sus derechos humanos [...]"en caso de que algún administrador de justicia no se aplique este protocolo y se viole algún tipo de derechos con relación a las mujeres y personas de orientaciones sexuales distintas, incluso, pueden ser objeto de denuncias penales" (TRIBUNAL SUPREMO DE JUSTICIA, 2017).
} 
O objetivo do protocolo consiste em orientar as magistradas e os magistrados a respeito do que deve ser observado para que seja possível julgar com uma perspectiva de gênero, ao passo que elabora diretrizes para que as decisões proferidas não apresentem estereótipos.

É possível identificar na medida proposta a procura por uma alteração profunda na atuação dos entes estatais e da sociedade como um todo, ao passo que a busca é pelo fim dos estereótipos. Diante da formação patriarcal da sociedade, constitui um desafio para as instituições reconhecer práticas baseadas em vieses, tendo em vista que tais preceitos estão arraigados culturalmente e, em reiteradas oportunidades, são considerados como normais (NASCIMENTO, 2012, p.68).

Para incentivar a atuação de acordo com os parâmetros proposto e vislumbrar o nível de absorção pelas operadoras e pelos operadores do direito em relação ao protocolo apresentado, o Comitê de Gênero do Órgão Judicial promoveu um concurso de sentenças para ser possível analisar a aplicação prática do quanto proposto. Para ser possível a realização da competição foi publicado inclusive um manual contendo a metodologia, o qual detalhava como deve ser realizado um julgamento com perspectiva de gênero.

Além dos órgãos oficiais, existem diversas instituições que buscam combater a violência de gênero na Bolívia, sendo que, para fins de desenvolvimento do presente trabalho, foi selecionada para análise a atuação da Articulación Regional Feminista, composta por uma aliança de instituições feministas.

Dentre os trabalhos desenvolvidos é possível identificar uma iniciativa similar à do comitê boliviano, a qual consiste em um observatório de sentenças. $\mathrm{O}$ intuito é identificar como cada uma das decisões trata os direitos das mulheres, o que demonstra, mais uma vez, a existência de iniciativas com o intuito de identificar a atuação prática do Poder Judiciário em relação à perspectiva de gênero.

Com isso é possível verificar que a questão da violência de gênero não é assunto que passa despercebido pelas autoridades e pelas instituições bolivianas, as abordagens buscam analisar a realidade local e, a partir disso, impor discussões a respeito da temática e desconstruir padrões de atuação das autoridades com o intuito de alterar as construções sociais a respeito da posição social das mulheres. 


\section{CENÁRIO ATUAL dA VIOLÊNCIA DE GÊNERO NO ÂMBITO DO PODER JUDICIÁRIO}

Após a compreensão dos conceitos teóricos e toda a evolução para alcançar a perspectiva atual do feminismo na Bolívia, é necessário vislumbrar os seus reflexos na realidade do Poder Judiciário, a partir do que será possível identificar como os elementos identificados pelo feminismo como cruciais para a construção de um cenário de opressão às mulheres refletem na realidade das autoras, dos réus e na construção do processo decisório das magistradas e dos magistrados.

\subsection{Metodologia}

Diante do engajamento das instituições em relação ao fomento à reflexão sobre violência de gênero, a Articulación Regional Feminista desenvolveu em seu site ${ }^{2}$ um observatório no qual é possível ter acesso a decisões proferidas nos países latino-americanos.

Para que fosse possível ter acesso às decisões proferidas pelos tribunais bolivianos, foi selecionado o campo "Observatório de Sentencias Judiciales", a partir do que é possível selecionar o país "Bolivia". Com isso foi apresentado o banco de dados de sentenças relacionadas ao direito das mulheres.

Em cada uma das sentenças há indicação do tribunal que a proferiu; data; tema; descrição; uma introdução sobre o caso, além de uma classificação representada por "sinais de positivo com a mão ${ }^{3 "}$ para cima ou para baixo a depender do posicionamento da decisão em relação aos direitos das mulheres.

Para realizar a seleção das sentenças que serão analisadas, foi observado o tema e a descrição, sendo que para realizar a seleção das sentenças bolivianas foram observados os seguintes critérios: foram selecionadas as decisões que possuíam unicamente tema "violencia contra las mujeres", sem descrição ou que conjugavam o tema "violencia contra las mujeres" com a descrição "violencia intrafamiliar" ou "violencia doméstica".

Importante ressaltar que não foi realizado recorte temporal, tendo em vista a presença uma quantidade reduzida de sentenças.

\footnotetext{
${ }^{2}$ Disponível em: http://www.articulacionfeminista.org/a2/index.cfm?aplicacion=APP003

${ }^{3}$ Sinal realizado com o polegar de uma das mãos.
} 


\subsection{Análise jurisprudencial}

A análise de decisões possui como objetivo identificar os elementos que foram essenciais para a tomada de decisão, bem como verificar como a posição social dessas mulheres é retratada pelo Poder Judiciário.

Das sete sentenças selecionadas, uma foi descartada pois estava ilegível. Das seis sentenças restantes, duas eram referentes à separação do casal e envolvia atos de violência contra filhas, porém, a temática não foi o foco da decisão. Com isso, quatro decisões trataram propriamente da questão da violência em decorrência do gênero, tanto nos fatos, quanto na fundamentação e no dispositivo.

Nas quatro oportunidades a situação envolvia violência do companheiro em face da companheira.

No primeiro caso analisado, foi ajuizada demanda diante da ocorrência de violência física e psicológica em situação na qual o réu estava sob efeito de bebidas alcóolicas. Os fatos foram confirmados pelo réu e foi apresentado relatório médico comprovando as consequências da violência, diante do exposto, em primeira instância o julgamento foi procedente e foi determinada a prisão pelo período de dois dias.

$\mathrm{Na}$ segunda demanda foram apresentadas queixas de violência física, as quais acarretaram a prisão do réu. A decisão é referente ao habeas corpus interposto por ele sob a alegação de que não foi preso em flagrante, motivo pelo qual possuía direito à liberdade. Ressalte-se que em nenhum momento o réu faz referência aos fatos, o embasamento é unicamente em relação às circunstâncias a partir das quais foi preso. A partir do exposto, com base no entendimento de que não houve flagrante de delito, o habeas corpus foi julgado procedente.

No terceiro processo são relatadas violências física, sexual e psicológica. Mesmo com o depoimento da vítima e de testemunhas a respeito da ocorrência de violência física, não houve reconhecimento da sua ocorrência, tendo em vista que as testemunhas se confundiram a respeito da data de ocorrência dos fatos. Ainda, em relação à violência sexual, mesmo tendo sido apresentados relatórios médicos comprobatórios, a mesma não foi reconhecida. $\mathrm{O}$ reconhecimento ocorreu apenas em relação à violência psicológica, tendo em vista a apresentação de laudo técnico comprovando a sua ocorrência, porém, o reconhecimento foi no 
sentido de que a violência psicológica ocorreu de forma recíproca, motivo pelo qual toda a família deveria realizar tratamento com profissional.

$\mathrm{Na}$ quarta demanda objeto de análise os relatos eram de violência física e psicológica, embasadas em diversos testemunhos de pessoas próximas à autora, tendo em vista ela não buscou ajuda médica, já que dependia financeiramente do réu e não queria correr o risco de perder a guarda de sua filha. A decisão foi pelo reconhecimento da ocorrência de violência física e psicológica, e como pena foi imposta multa. Em segunda instância foi anulada a sentença em relação à violência psicológica.

Após o breve relato dos casos analisados, é possível identificar que a despeito de todos os esforços tanto das feministas bolivianas quanto das autoridades e das instituições locais, a violência de gênero ainda é uma realidade.

Importante ressaltar ainda que em nenhuma das oportunidades a condenação foi embasada unicamente na palavra da autora, sempre foram apresentadas outras provas para construção da convicção. O que chama a atenção é que mesmo quando apresentadas provas da ocorrência de violência, nos casos três e quatro a condenação ocorreu de forma parcial e com ínfimas consequências práticas para a realidade dos réus, fato que comprova como o patriarcado e defesa do homem estão presentes na sociedade, o que aparece de forma extremada no caso três, tendo em vista que mesmo diante de evidências documentais em relação à violência sexual não ocorreu condenação em relação a ela.

Dos casos analisados merece destaque ainda a fala da autora na demanda quatro. Mesmo diante da constante violência à qual era exposta, o medo e a dependência financeira foram aspectos determinantes para não denunciar em momento anterior. A construção social que confere ao homem a posição de provedor da família ainda é uma realidade enfrentada por muitas mulheres e que possui reflexos diretos no momento da tomada de medidas em relação à ocorrência de violência.

Ao analisar os casos práticos, é possível vislumbrar o quanto ainda há a progredir e, principalmente, as consequências que o patriarcado ainda exerce sobre a construção social, tanto nas atitudes dos réus, quando no receio das autoras em realizar a denúncia e, principalmente, nas decisões das juízas e dos juízes que mesmo diante de provas, muitas vezes, presam pela palavra do homem em detrimento das comprovações da mulher.

\section{CONSIDERAÇÕES FINAIS}


É possível identificar uma crescente em relação à evolução do feminismo na Bolívia, as abordagens visam trazer as problematizações, as lutas para o cenário do país e para especificidades que devem ser levadas em consideração para que ocorra a evolução dos direitos das mulheres e a desconstrução de padrões sociais.

Importante ressaltar ainda que a luta das mulheres no cenário boliviano não fica adstrita às discussões teóricas sobre o tema, é possível identificar um real envolvimento das autoridades com o intuito de ampliar as discussões e tomar medidas para a construção de uma sociedade livre da colonialidade e do patriarcado.

A representatividade de Evo Morales, como descendente dos povos originários bolivianos, conferiu ainda mais força para a busca pelo fim da colonialidade no âmbito do feminismo. Tal fato foi responsável inclusive por impulsionar o crescimento do feminismo comunitário, um dos principais movimentos bolivianos feministas.

Nesse sentido, é possível identificar que a questão sobre a posição da mulher na sociedade boliviana e as dificuldades enfrentadas são observadas sob uma perspectiva histórica e cultural. As abordagens buscam compreender como ocorreu a construção social atual e quais medidas podem ser tomadas para uma alteração profunda dos paradigmas.

Ao adentrar a questão da violência de gênero, a qual está intimamente relacionada à posição da mulher na sociedade e aos abusos ainda existentes, é possível identificar o esforço das autoridades e das instituições para a imposição de medidas com o intuito de dar visibilidade ao tema e propor uma mudança de perspectiva.

A atuação dos órgãos oficiais não se restringiu à promulgação de leis, é possível identificar uma busca por alterações no dia-a-dia, com base no fim dos estereótipos e do que é aceitável em relação à posição da mulher na sociedade. As autoridades bolivianas compreenderam que não basta a tomada de medidas formais para o fim da violência de gênero e dos abusos sofridos em decorrência da posição social que as mulheres se encontram.

Mesmo diante de todos os esforços, as decisões mostram o quanto ainda é necessário evoluir e quanto o patriarcado está enraizado não só nas atitudes da autora e do réu, mas propriamente no sistema judiciário, na forma de construção do raciocínio e na fundamentação das juízas e juízes.

Apesar de ser evidente que ainda não foi alcançado o patamar desejado em termos de desvencilhamento da colonialidade e do patriarcado, é possível identificar que medidas estão 
sendo tomadas para isso e que as inciativas possuem uma visão entrelaçada com as teorias feministas bolivianas que buscam a representação das suas mulheres com as suas realidades e origens particulares.

\section{REFERÊNCIAS}

AGÊNCIA BRASIL. Bolívia vai declarar alerta nacional por feminicídios. Publicado em 09 jan. 2020. Disponível em: https://agenciabrasil.ebc.com.br/internacional/noticia/202001/bolivia-vai-declarar-alerta-nacional-por-feminicidios. Acesso em 09 abr. 2020.

ALFARO, Raquel. Mujeres Creando Comunidad: Feminización de la comunidad. Revista de estúdios bolivianos, 2018-2010, v.15-17, p. 211-236.

ALlión, Virginia. Debates em el feminismo boliviano: de la Convención de 1929 al “processo de cambio". La Paz: Ciencia y cultura. 2015.

CARRASCO, Marianela Agar Diaz. ¡De empleada a ministra!”: despatriarcalización en Bolivia. Quito: Revista de Ciencias Sociales, 2013, v.17, p. 75-89.

CYPRIANO, Breno. Construções do pensamento feminista latino-americano. Florianópolis: Revista de Estudos Feministas, 2013.

DÁVALOS, Ximena. Balance de la Ley 348. Estudios Bolivianos, 2014. v.21.

FEMENÍAS, Maria Luisa. Esbozo de um feminismo latinoamericano. Florianópolis: Revista de Estudos Feministas, 2007.

GUZMÁN, Adriana; PAREDES, Julieta. El tejido de la rebeldía. ¿Qué es el Feminismo Comunitario? Bases para la despatriarcalización. La Paz: Mujeres Creando Comunidad, 2014.

JESUS, Milena Santos; SACRAMENTO, Sandra Maria Pereira. A abordagem conferida ao sexo e gênero nas distintas ondas feministas. Revista Café com Sociologia, 2014, v.3.

LEGATES, Marcele. In their time: A history of feminism in western society. New York: Routledge, 2011.

LUGONES, María. Rumo a um feminismo descolonial. Revista de estudos feministas, 2014, p. 935-952.

MACIEL, Thaynná Soares; SILVA NETO, Antônio Carlos Batista. Resistência das mulheres latino-americanas: Ni uma a menos. Campina Grande: Realize, 2018, v.2.

MATOS, Marilise. Movimento e teoria feminista: É possível reconstruir a teoria feminista a partir do sul global? Curitiba: Revista de Sociologia e Política, 2010, v.18, n³6, p. 67-92.

NASCIMENTO, Luana Regina Ferreira do. Aplicação da Lei Maria da Penha: um estudo sobre estereótipos de gênero no Judiciário. 83 f. 2012. Tese (Mestrado em Política Social) Instituto de Ciências Humanas, Universidade de Brasília, Brasília, 2012.

ORTIZ, Jenny Ybarnegaray. Femnismo y descolonización. Beunos Aires: Nueva Sociedad, 2011, p $159-171$.

PAREDES, Julieta. Despatriarcalización: Uma respuesta categórica del feminismo cumunitario. Revista de Estudios Bolivianos, 2015, v. 21, p. 101-115.

PORTAL DE IMIGRAÇÃO, Ministério da Justiça. Observatório OBMigra. Disponível em: https://portaldeimigracao.mj.gov.br/pt/dados. Acesso em 29 mar. 2020.

TRIBUNAL SUPREMO DE JUSTICIA. Justicia lanzó protocolo para defender la vida, dignidad y los derechos de mujeres. Publicado em 07 mar. 2017. Disponível em: 
https://tsj.bo/justicia-lanzo-protocolo-para-defender-la-vida-dignidad-y-los-derechos-demujeres-y-lgbti/. Acesso em 20 mar. 2020.

ZANINI, Cecil Jeanine Albert. Crítica feminista: Uma contribuição para a história da literatura. Rio Grande do Sul: Editora PUCRS, 2011. 